University of South Carolina

Scholar Commons

$8-25-2010$

\title{
Embedded Information Literacy in the Basic Oral Communication Course: From Conception Through Assessment
}

\author{
Kari D. Weaver \\ University of South Carolina - Aiken, kariw@usca.edu \\ Penni M. Pier \\ Wartburg College, penni.pier@wartburg.edu
}

Follow this and additional works at: https://scholarcommons.sc.edu/

aiken_gregg_graniteville_library_facpub

Part of the Library and Information Science Commons

\section{Publication Info}

Postprint version. Published in Public Services Quarterly, Volume 6, Issue 2-3, 2010, pages 259-270.

This is an electronic version of an article published in Public Services Quarterly, 6(2/3), 259-270.

Public Services Quarterly is available online at http://www.tandfonline.com/loi/wpsq20

http://www.tandfonline.com/doi/full/10.1080/15228959.2010.497455

Weaver, K.D., \& Pier, P.M. (2010). Embedded information literacy in the basic oral communication course:

From conception through assessment. Public Services Quarterly, 6(2/3), 259-270. DOI: 10.1080/

15228959.2010.497455

(c) 2010 by Taylor and Francis

This Article is brought to you by the Gregg-Graniteville Library at Scholar Commons. It has been accepted for inclusion in Faculty Publications by an authorized administrator of Scholar Commons. For more information, please contact digres@mailbox.sc.edu. 
Embedded Information Literacy in the Basic Oral Communication Course: From Conception Through Assessment

Kari D. Weaver

University of South Carolina Aiken

\&

Penni M. Pier

Wartburg College 


\begin{abstract}
This paper explores the process of embedding information literacy into a basic oral communication course. Discussion includes student performance as an impetus for change, collaborative course design between the oral communication teaching team and instructional librarians, and assessment initiatives. Suggestions for future collaborative work are articulated.
\end{abstract}

Keywords: embedded information literacy, oral communication, assessment 


\section{Introduction}

In the past few decades institutions of higher education have focused attention on the first-year curriculum and the competencies students are exposed to when they enter the academy. The basic oral communication course and information literacy programs have been an integral part of this discussion (Meyer et.al, 2008). Wartburg College was no exception to this national trend. While the concept of information literacy was not foreign to the faculty, librarian involvement in course instruction was seen as additive rather than integrative.

In the wake of a campus wide discussion of the $21^{\text {st }}$-century learner, the teaching team of the basic oral communication course was faced with some harsh realities; students were not performing at levels that were deemed acceptable to the team. It was decided that the root cause of many of the deficiencies discussed was inadequate exposure to information literacy skills within the course itself, arguably a function of course construction and not a commentary on the capabilities of the instructional librarians. Exacerbating this problem was the fact that the course lasts for only seven weeks and there was no guarantee that a student taking the course would have been exposed to information literacy instruction prior to constructing speeches for the class. In light of all of these challenges, the basic oral communication teaching team opted to restructure the course. Integral to the reconstruction was the decision to embed an instructional librarian in the course assessment, design and implementation process.

What follows is an account of the impetus for the change, how the American Association of School Librarians' standards for the $21^{\text {st }}$-century learner was a guiding principle in the re-design process, the decision to put information literacy at the core of the course, how the team was formed, the importance of the embedded librarian, lessons learned from assessing the course post-implementation and finally some conclusions about the future of embedded information literacy within the basic oral communication course. 


\section{Student Performance as an Impetus for Change}

As is standard practice, the oral communication teaching team met in the spring semester of 2009 to assess the course for its efficacy with regard to providing basic public speaking skills to the student population. As it had been four years since the custom workbook used to supplement the course had seen any substantial changes, the team was charged with assessing that document as well as the course structure in general. Of the many issues the team discussed, one stood out as being of the utmost urgency: the assignments and tasks associated with the course didn't reflect the learning style of the 21 st century learner. It was clear to the teaching team how the assignments were designed to enhance learning, but those connections were not always clear to the students in the class. It was the judgment of the team that if students could not see the value added in the required assignments they would likely dismiss the importance of the course altogether. Therefore, organization and integration of assignments designed to assist students in the construction of their speeches were given the highest priority.

In order for the team to restructure existing assignments, or to create new, the team identified several deficiencies in student speeches. A lack of critical thinking and cogent argument construction in student speeches was identified by the team as the most glaring deficiency. Additionally, a scarcity of salient information and relevancy to the audience contributed to incoherent or fallacious argumentation. The team also concluded that there was little breadth or depth to the research and sources students were relying upon for speech construction and when sources were used students rarely cited them properly. Finally, the team expressed disappointment in the levels of creativity and challenge with regard to topic selection. It was clear following the assessment workshop that information literacy, or lack thereof, lay at the heart of all of the aforementioned issues surrounding lackluster speech presentations. Considering that the oral communication course is primarily taken by first year students, and as Jacobson and Mark (2000) argue first year students are 
not often information literate which is essential to the nature of a public speaking course, these conclusions are not surprising.

The Twenty-First Century Learner and Oral Communication as a Nexus for the ASSL Standards

Like most institutions of higher education, the challenges of educating the 21 st century learner have been of particular importance at Wartburg College. Through a series of convocations and workshops meant to stimulate discussion about the learning styles of the contemporary student, a campus wide discussion concerning best teaching practices had begun in earnest in the fall of 2009. One such workshop provided by the library faculty centered on the American Association of School Librarians' (2007) standards for the 21st century learner. Faculty from a variety of disciplines were challenged to evaluate current teaching practices in light of the four overarching goals outlined by the ASSL: 1 . inquire, think critically, and gain knowledge; 2 . draw conclusions, make informed decisions, apply knowledge to new situations, and create new knowledge; 3. share knowledge and participate ethically and productively as members of our democratic society; and 4. pursue personal and aesthetic growth. A vital and inextricable link exists between oral communication and information literacy and while that fact had always been acknowledged by the oral communication faculty at Wartburg, a lack of clear understanding about current best practices in library science, coupled with the challenges and lack of opportunities for collaboration in meaningful and practical ways, served as a roadblock for an integrative approach to information literacy within the basic oral communication course.

What became increasingly clear among the team charged with assessing and restructuring the oral communication course, was that the four global standards outline by the ASSL echoed the concerns that the teaching team expressed during the initial assessment of the course. The oral communication teaching team decided to use the AASL standards as a guide for restructuring the information literacy components of the course because they more accurately reflect the competencies we would like to see in our students. 
While the Association of College and Research Libraries (ACRL) standards have some important commonalities with the AASL standards, the ACRL standards do not effectively address the multiple literacies that are required in a basic public speaking course. Additionally, because this course is intended for first year students the AASL standards serve as a natural transition from the high school environment and reinforce skills and terminology that are more likely to be accessible to the first year student. Information Literacy at the Core of the Re-Vision

As previously mentioned, the oral communication teaching team was convinced that sub-par information literacy skills were responsible for the deficiencies being observed throughout all sections of the course. Once it was established that information literacy instruction was a core component to the speechmaking process, and that it was in need of attention, it became important to discuss what the best practices were relative to integrating those literacies into the course structure. It was decided that information literacy would be embedded within the curriculum and that each speech that was assigned for the course would have its own information literacy component. An embedded approach was adopted for a variety of reasons. Because there are three formal speeches in the course each student has multiple exposures to information literacy instruction which is important for skill refinement and retention. The speeches required for the course become more complex with each new speech assignment, where skills previously learned are reinforced and new skills are introduced. The same approach was utilized with regard to embedding information literacy components into the course. The benefits of such intentionality in embedding an information literacy component into speech assignments are two-fold; it illustrates to the student that research and information literacy skills are an integral part of the organic process of speech construction and it allows for the oral communication teaching team to isolate and address any deficiencies the information literacy skills.

The oral communication faculty espoused the belief that if embedded information literacy was a necessary and vital component to a re-visioning of the course, it could not be 
accomplished in isolation from the instructional librarians. It was decided that not only would information literacy instruction be embedded in the actual course materials, but that a librarian embedded in the reorganization of the course would not only be beneficial but pedagogically imperative. The embedded librarian would be in a position to provide commentary and guidance on the development, assessment and ongoing instruction relative to the library resources at the students' disposal. Additionally, the embedded librarian would be aware of any new pedagogical or technological approaches to information literacy instruction that would better serve the student population.

\section{Team Formation}

The concept of faculty and librarian collaboration is far from a new idea and such partnerships have occurred at forward thinking institutions like Earlham College for nearly thirty years. However, when taking a closer look at the steps that led to success in such partnerships, it was found that, "...the library and course-integrated instruction are promoted through the power of relationships" (Walter, 2000). Thus a focus on forming relationships led to the creation of a team dynamic that was at the heart of the Wartburg College collaboration. The team was highly motivated by the possibilities of working jointly and collectively wanted to undertake collaborative course construction for three primary reasons. First, a prescriptive curriculum was needed to meet both internal and external standards and provide consistency across numerous sections of the course. Second, in developing a prescriptive curriculum, instructor input and buy-in was essential to effective implementation. Third, the concept of embedded information literacy in this context is extremely complex and it was of vital importance that the individuals teaching the course both understand and actively create the integrated content.

Through numerous meetings, a deep discussion of the ASSL standards and an early SWOT (strengths, weaknesses, opportunities and threats) analysis the foundation of teamwork was forged. However, the glue that strengthened the bond was a set of common 
learning outcomes and objectives for the course. The learning outcomes were:

- You will better understand informative and persuasive oral communication.

- You will be able to better construct and deliver oral presentations.

- You will be able to better integrate presentational media into your communication.

While none of these outcomes explicitly articulated information literacy competencies, the implicit connections between the AASL standards and the course outcomes are expansive. Some standards, such as to "use knowledge and information skills and dispositions to engage in public conversation and debate around issues of common concern," or to "use interaction with and feedback from teachers and peers to guide own inquiry process," were inherently met in the course as they reflect best practices in oral communication pedagogy. Because of the campus culture, it was expected that other basic information literacy skills including; "find, evaluate, and select appropriate sources to answer questions, seek divergent perspectives during information gathering and assessment, employ a critical stance in drawing conclusions by demonstrating that the pattern of evidence leads to a decision or conclusion, and organize knowledge so it is useful," had been introduced through courses in the information literacy across the curriculum plan, but were not previously a main focus of such co-curricular efforts. Despite this fact, and through SWOT analysis, the oral communication teaching team identified five other standards that could be met through the embedded course design, specifically: "collaborate with others to broaden and deepen understanding; conclude an inquiry-based research process by sharing new understandings and reflecting on the learning; demonstrate teamwork by working productively with others; connect ideas to own interests and previous knowledge and experience; and recognize the limits of own personal knowledge" (AASL, 2007). 


\section{The Embedded Librarian}

Though forming the team was key to the process of collaborative course creation; it was the constant presence of a librarian on the team that allowed a fully embedded product to emerge. "Partnership with librarians might mean that faculty use tools or other components achieving the agreed-upon learning objectives themselves rather than relying upon the traditional in-class library instruction" (Dewey, 2004). This collaboration utilized both traditional in-class library instruction and multiple alternative integrated learning objects within the framework of the course. Some content was exclusively designed by the librarian and then collaboratively edited within the group, and some content was created by the teaching faculty with direct input from the librarian.

The embedded librarian was used throughout the design process to find creative ways in which to integrate information literacy instruction and content for implementation into the course. The librarian designed worksheets that were integrated into the course workbook, with an information seeking activity for each speech assignment: which included an informative speech, a persuasive speech and a cross-examination policy debate. The first worksheet, paired with the informative speech, focused on content currency and source evaluation. The second, paired with the persuasive speech, introduced basic data literacy and use. The third, paired with the debate, asked students to research and articulate background information on the debate resolution. Furthermore, the worksheets were designed to work in tandem with the two other assignments required for each speech; a topic worksheet and an outline with integrated source citations. Citations for the class were standardized using American Psychological Association citation style and a worksheet to provide an introduction to the APA format. These course assignments both fit into a larger framework of the speech preparation process and, through grading, placed a heavy importance on the content.

In addition to the embedded assignments, the students were required to attend a traditional in-class library lecture delivered by the librarian. This replaced an existing lecture 
Running head: EMBEDDED INFORMATION LITERACY IN THE ORAL COMMUNICATION COURSE 10

on finding and using information and allowed the librarian to design hands on work time for the class relative to their informative speech assignment. The librarian teaching the in-class lecture was further embedded into the campus culture as nearly all students would experience an instruction session with them in their first two years of study. To compliment the in-class lecture, the oral communication teaching team also utilized the entire staff of instructional librarians in a creative way to deliver course content. In preparation for the debate, each group of students was assigned a pre-determined resolution and a librarian with which to meet outside of class for an introduction to appropriate research resources. Every instructional librarian at the college was assigned one debate resolution and became the resource expert on that topic. Students were required to exhibit time management and personal responsibility by arranging a meeting with the designated librarian and completing a worksheet for the librarian's review on their debate resolution prior to the meeting. The meetings provided a unique opportunity for the instructional librarians who were able to address the use and abuse of Wikipedia ${ }^{\mathrm{TM}}$ as a source of information at the college level during the meeting.

Communication between the oral communication teaching team and the instructional librarians became a major point of consideration during the design process. For the information literacy concepts to be truly embedded there needed to be a single repository which all stakeholders could easily access the librarian-generated content. To accomplish this goal, the embedded librarian created an electronic research guide as the central communication tool (http://knightguides.wartburg.edu/ca112). The research guide was coedited by the instructional librarians and was used to supplement both in-class instruction and meetings with the debate groups. The research guide allowed seamless electronic communication between the teaching team, instructional librarians, and students. The research guide could also be easily linked to the campus course management system for greater synergy. 
Running head: EMBEDDED INFORMATION LITERACY IN THE ORAL COMMUNICATION COURSE 11

Finally, the importance of the information literacy content was emphasized by incorporating questions from the in-class instruction, debate group meetings, and integrated worksheets into the final examination. The idea that students were responsible for, and would be tested over the embedded information literacy content, improved student motivation and kept the in-class instruction from being perceived by the students as spurious. It is also important to note that information literacy techniques, such as concept mapping, were integrated into the course content. Several of the assignments illustrating or demonstrating literacy techniques were created by members of the oral communication teaching team at the suggestion of the embedded librarian during the design process. The librarian presence in the course design process was a true reflection of embedded librarianship in the academic environment of the 21st Century as Jacobson and Xu (2004) so eloquently stated, "Instructors obviously do not want students to learn to be information literate just for the isolated pleasure of information literacy, but would like student to use their new knowledge (pg. 26)." Through creation, implementation and grading, librarians were an integral part of the entire collaborative process. Though this initiative led to greater communication and understanding across the college campus, further assessment initiatives were undertaken to provide independent confirmation of the impact from the project.

\section{Assessment as an Indicator of Success}

Ongoing assessment was identified early on as a vital component of the re-visioning and restructuring process. Both formal and informal measures of assessment were used to make determinations with regard to the efficacy of the changes made and to make decisions about which elements of the course needed further attention. Specifically, the oral communication teaching team collected and relied upon instructor observations, qualitative self-report data from students, quantitative data monitoring traffic in the library and campus wide conversations with faculty about the course for assessment purposes. 
Running head: EMBEDDED INFORMATION LITERACY IN THE ORAL COMMUNICATION COURSE 12

\section{$\underline{\text { Instructor Observations }}$}

Three general observations were reported by the oral communication teaching team; topic creativity, higher quality of research and more focused argumentation. Lack of topic creativity was cited as problematic in the initial discussion of the course deficiencies by the teaching team. Further discussion with the embedded librarian suggested that students may default to topics and popular search engines in the construction of their speeches because it is familiar to them, which can result in speech topics that are less challenging for the students and of little interest to their audience. Therefore, an age limit of three years was imposed on the informative speech topic. Placing this limit on the topics that students were allowed to pursue on their first speech had both the outcome desired by the faculty, more creative topics, but also had an unanticipated, but welcome, information literacy outcome. By making recency a criterion for topic selection students had to use a variety of search methods, resources and utilize source evaluation skills to find the requisite number of sources. While on the face a dearth of sources might seem to be a negative outcome of such time restrictions, it actually allowed the students to become more intimately familiar with the topics because they were not overwhelmed by the quantity of information. Because students had a positive experience with their first speech they were much more confident with subsequent speeches which had more challenging research requirements. In addition to more creative topics, the teaching team reported that the research cited in the speeches was of a markedly higher quality than that seen prior to the implementation of the embedded information literacy assignments. This, coupled with higher scores received by students on the sections of the grading rubrics that evaluate source usage during the speech, would seem to indicate that the changes made to the course with regard to embedded information literacy assignments were having a measurable positive impact. Finally, the teaching team was pleased to observe that, compared with the course prior to the changes; students were making strides in the structure of their arguments. The 
Running head: EMBEDDED INFORMATION LITERACY IN THE ORAL COMMUNICATION COURSE 13

arguments were more focused, specifically with regard to making the relationship between the claims being made and the evidence used to illustrate or support those claims more explicit. This outcome was due to two factors; increased instructor focus on argument structure and an embedded information literacy assignment targeting argument construction. The teaching team created explicit and extensive lecture guidelines which were used when covering the elements of argumentation and debate. This shared knowledge and lexicon made it easier for both instructors and students to dialog about arguments and supporting evidence. Additionally, in consort with the embedded librarian, an assignment was created that asked students to diagram an argument that clearly identified the claim, supporting material and the connection between the two. This assignment served as a template for the students to follow while constructing their speech, resulting in more focused argumentation.

\section{$\underline{\text { Student Self-Report Data }}$}

A formal measure of assessment was embedded into the course structure to ensure that every student provided feedback on the information literacy instruction. As previously mentioned, students met with a librarian as a requirement for the cross-examination policy debate assignment. After the meeting had occurred each student completed a "3-2-1" assessment tool. They were asked to list three new things they discovered after meeting with the librarian, two sources or techniques that they would use for researching the debate resolution and one thing that they learned that they will use when doing research in the future. The responses were collected by the course instructors and were analyzed by the director of the oral communication course. Three general themes emerged from this qualitative data: a greater knowledge of search terms and techniques; how to more effectively use data bases; and how to properly use Wikipedia ${ }^{\mathrm{TM}}$. Students overwhelmingly reported that they learned a great deal about how to use a variety of search terms and techniques to find the information that they were seeking. For example, several students 
Running head: EMBEDDED INFORMATION LITERACY IN THE ORAL COMMUNICATION COURSE 14

reported feeling more confident in conducting Boolean searches after meeting with the librarian. Students also indicated that they were not aware of all of the databases that were at their disposal, nor were they aware of how beneficial they could be. Students reported that using a database, such as the Educational Resources Information Center or Lexis/Nexis ${ }^{\mathrm{TM}}$, could not only yield the best results but save them a great deal of time because of the specificity with which they could set the search parameters. As previously mentioned, one of the purposes of the individual meetings with the librarians was to address the use and abuse of Wikipedia ${ }^{\mathrm{TM}}$ in scholarly research. It is clear from the student self-report data that this message was received and internalized by the students. They expounded at great length about how information makes its way to Wikipedia $^{\mathrm{TM}}$ and what implications that may have on content evaluation. It is clear from the self-report data that students found the information sessions useful and the content goals set for those sessions were met. Additionally, it can be argued that the embedded model allows the teaching and library teams to provide highly specialized and tailored information literacy sessions to meet the expressed needs of the course as well as provide the flexibility to address concerns as they arise throughout the duration of course.

\section{Student Traffic in the Library}

Librarians have seen a $53 \%$ increase in student requests for individual librarian assistance combined with an upward trend in reference statistics. While it is not possible to say these changes were delivered solely by the embedding process, it would be impossible to state the group debate meetings have not contributed to these trends. Because students discover and assess the value of meeting with a librarian early in their college career, they are more likely to contact a librarian with questions or request an individual librarian by name later. Such requests have become so pervasive; the library now includes a weekly reference calendar on the desk so students can check to see when their preferred librarian 
Running head: EMBEDDED INFORMATION LITERACY IN THE ORAL COMMUNICATION COURSE 15

is on reference duty. Due to the perceived increase in library traffic, the teaching team is exploring software that can be used to more accurately track the data.

\section{Campus Reaction}

The director of the oral communication course and the embedded librarian have been invited to give multiple presentations about the changes made to the course to their colleagues. The response has been overwhelmingly positive and there is anecdotal feedback to suggest that there is some skill transfer and cross over to other courses. More systematic and formal assessment measures need to be implemented to see if these anecdotal reports are statistically significant and accurate. An unexpected, but welcome, outcome of this collaboration has been a sincere curiosity on the part of faculty members across campus to engage in a dialogue about the efficacy of and satisfaction with the process of embedding information literacy into a course. It is the intention of the director of the oral communication course and the embedded librarian to continue efforts to seamlessly integrate information literacy as a vital and central component of the course as well as to extend an invitation to the larger campus community to actively pursue avenues for information literacy integration into existing curriculum.

\section{Conclusion}

While an ambitious project, it is the opinion of the educators involved that the effort put forth yielded some impressive results. Success can be attributed to two fundamental factors; an initial conversation outlining perceived deficiencies and the overarching ASSL framework to give subsequent discussions surrounding curricular changes guidance and direction. Due to the collaborative nature of the project and the necessity of consistency of instruction among all sections of the basic course, it was important that all parties involved were able to articulate perceived deficiencies in the course as it existed at the outset of the project. This allowed the team to create a common language to facilitate discussion and create a common culture. The team adopted the ASSL standards as a framework to guide 
Running head: EMBEDDED INFORMATION LITERACY IN THE ORAL COMMUNICATION COURSE 16

their discussion because there was a synchronicity between the ASSL standards and what the team had articulated as best practices for oral communication. Additionally, the ASSL standards served as a point of reference between the oral communication teaching team and the library instruction team once the implementation of the information literacy components of the course began in earnest.

It is the belief of all of the educators involved in the process that embedded information literacy is not only appropriate for the basic communication course, but that the course was dramatically more successful due to the embedded information literacy components. Although the team is confident that this is the most effective model to use, there are some issues that need to be addressed. Construction of formal assessment tools to provide longitudinal data will be vital in the team's ability to assess the efficacy of the course. It may be necessary to add a quantitative element to the existing embedded assessment assignment in order to provide comparable data across sections. However, the team feels that both the qualitative and quantitative data need to be used in tandem in order to obtain an accurate view of student perceptions with regard to the embedded information literacy components.

In sum, the team and the college are committed to the theory and praxis of embedded information literacy as an integral component of the basic oral communication course. As it is the only course which all students are required to take that follows a standard curriculum, it presents a unique opportunity to expose students to an experience that emphasizes the inextricable link between information literacy and a liberally educated student. 
Running head: EMBEDDED INFORMATION LITERACY IN THE ORAL COMMUNICATION COURSE

\section{References}

American Association of School Librarians. (2007). Standards for the 21st-century learner. http://www.ala.org/ala/mgrps/divs/aasl/guidelinesandstandards/learningstandards/s tandards.cfm

Dewey, B. I. (2004). The embedded librarian: Strategic campus collaborations. In W. Miller \& R.M. Pellen (eds.), Libraries within their institutions: Creative collaborations (pp.518). Binghamton, NY: Haworth.

Jacobson, T. E., \& Mark, B. L. (2000). Separating wheat from chaff: Helping first-year students become information savvy. Journal of General Education, 49, 256-278.

Jacobson, T. E., \& Xu, L. (2004). Initial course design. In Motivating student in information literacy classes (pp. 23-41). New York: Neal-Schuman.

Meyer, K. R., Hunt, S.K., Hopper K. M, Thakkar, K. V., Tsoubakopoulos, K \& Van Hoose, K. J. (2008). Assessing Information Literacy Instruction in the Basic Communication Course. Communication Teacher Vol. 22(1), pp. 22-34.

Walter, S. (2000). Case studies in collaboration: Lessons from five exemplary programs. In D. Raspa and D. Ward (eds.), The collaborative imperative: Librarians and faculty working together in the information universe (pp.39-78). Chicago: Association of College and Research Libraries. 